\title{
Design Considerations for the Implementation of Tailings Based Wetcrete at Harmony's Target Mine
}

\author{
P.J. Le Roux Brentley Lucas and Associates (Pty) Ltd, Target Mine, South Africa \\ D.J. du Plooy SRK Consulting, Australia
}

\begin{abstract}
The Target Mine orebody is situated approximately $2400 \mathrm{~m}$ below surface and is accessed via a vertical shaft and decline system, totalling approximately $6000 \mathrm{~m}$ in length. This requires that all modes of transport be optimised. As a result of the heavy burden on the mine's logistical transport system, the mine was unable to deliver sufficient quantities of wetcrete material to the underground batching plant. This resulted in a relatively large backlog of wetcrete work building up over a number of years. The mine utilises a system of batching wetcrete underground using conventional material such as sand, cement and chemical additives.

Through creative thinking, a system was designed to replace the current wetcrete infrastructure with a surface batching plant where cycloned tailings are used to prepare a wetcrete mix on surface. This system promises not only to impact positively on the mine's logistical system, but also reduces the direct cost of supplying wetcrete material underground. This paper discusses the philosophy behind the design and implementation of tailings based wetcrete as well as the quality assurance requirements at Target Mine.
\end{abstract}

\section{Introduction}

Target mine is located approximately $270 \mathrm{~km}$ south-west of Johannesburg in the Republic of South Africa. Geologically, the mine is situated on the eastern boundary of the Witwatersrand basin and at the northern boundary of the Free State gold fields.

The reefs being mined currently at Target are the Eldorado reefs, mainly on the western limb of a synclinal structure. These consist of single and multiple reefs that are mined by various methods, including conventional tabular stoping and massive open stoping. The thickness of individual reefs varies from 0.5 to $3.0 \mathrm{~m}$. The dip of the reefs ranges from $0^{\circ}$ to $90^{\circ}$. The rock formations hosting the reefs are generally very competent, with widely spaced bedding planes. The reefs are mined at depths ranging from $1800 \mathrm{~m}$ to $2400 \mathrm{~m}$ below surface.

The mine has a state of the art backfill plant, which supplies cemented backfill to the underground operation for support of the open stopes.

Access to the orebody is through a vertical shaft and then through a 6-legged decline system, totalling approximately $6000 \mathrm{~m}$. All material is transported down this route in material cars using a monorail conveyance. This often creates a bottleneck situation in that not enough material can be transported down the mine to supply the underground wetcrete operation. As a result, a fairly large backlog of wetcrete work has been built up over a number of years. It was thus in the interest of mine stability that an alternative system of delivering wetcrete material had to be found.

\section{Development support strategy}

The aim of the development support strategy (Ras and Basson, 2002) at the mine is the following:

- Prevent local rockfalls.

- Reduce rockburst damage.

- Permit the tunnel or excavation to be used for its desired function, for its desired life, without interruption. 
- Be cost effective.

Hence the mine follows a strategy that requires all long-term tunnels to be supported with wetcrete to a total average thickness of $40 \mathrm{~mm}$.

The current wetcrete operation consists of a surface screening plant where the wetcrete aggregate (graded river sand) is screened before it is sent underground to an underground batching plant where cement and chemical additives are mixed together. The batching plant is situated approximately midway down the decline system, resulting in long transport distances of batched wetcrete material to the working areas of the mine.

A total of approximately $108 \mathrm{~m}^{3}$ of wetcrete material was required to meet the monthly demand. This equates to 270 materials cars per month ( \pm ten cars per day). The availability of classified tailings and a complete system of backfill ranges (backfill pipe system) to the underground operation provided an ideal opportunity to investigate a system of tailings based wetcrete. The aim of this investigation was to find an alternative wetcrete mix design that was possible to prepare on surface and that could be pumped to the working area through existing ranges. Similar technology is well known to the South African platinum mining industry (Van Vuuren, 2007) where cementitious slurry is pumped down mines to construct concrete packs.

A project task team consisting of senior production personnel, backfill plant operators and rock mechanics engineers listed the following approach to the investigation. The project would eventually follow a twotiered approach. While thorough research is done on pumping technology for a high density cementitious material, cycloned tailings will pumped into a holding tank at the current batching plant to allow implementation of the tailings based wetcrete system.

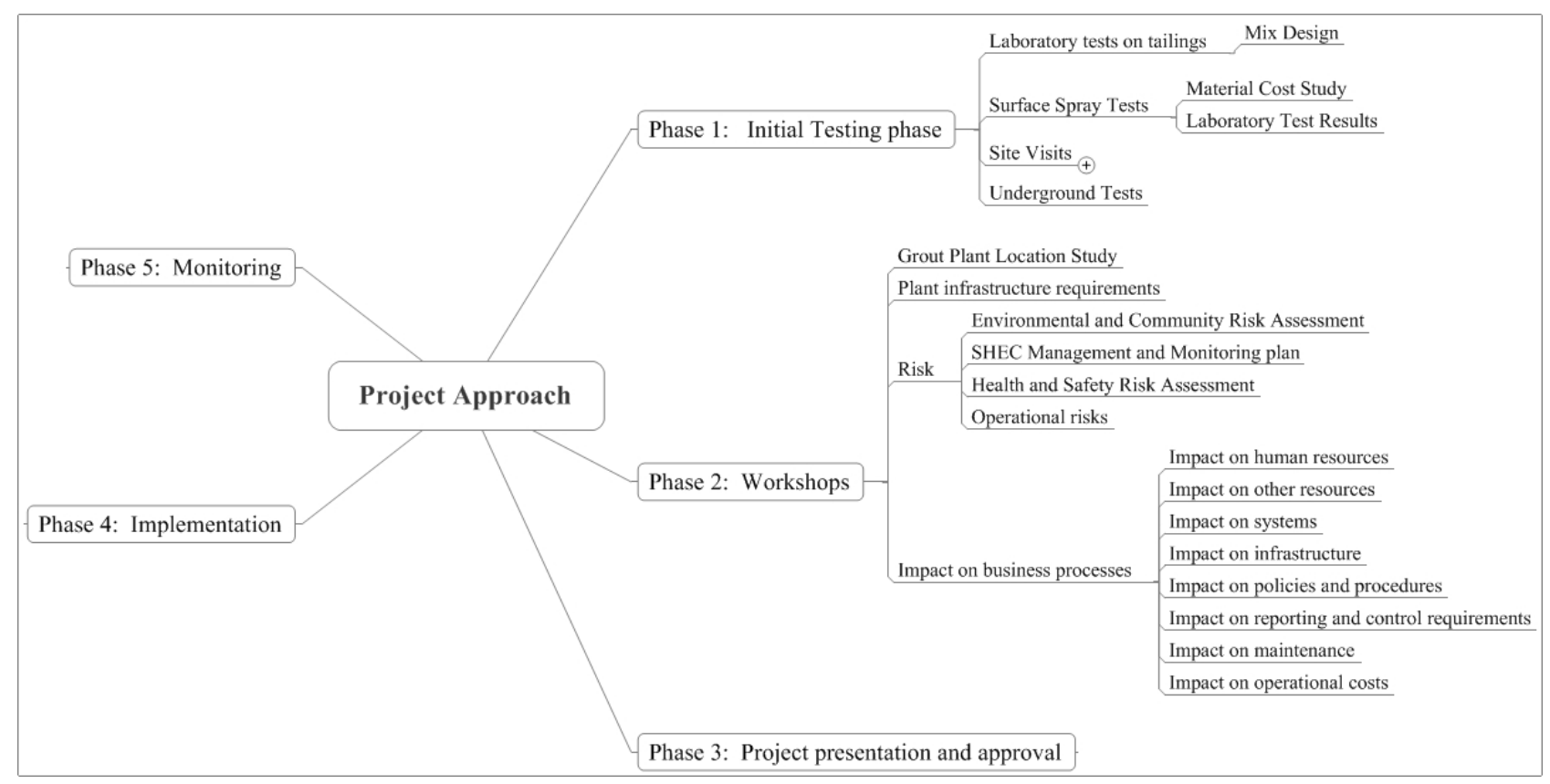

Figure 1 Project approach layout (Target mine, internal documentation)

\subsection{Initial testing}

The most important aspect of this project was to provide proof that tailings could actually be used as an alternative to river sand as aggregate material. In consultation with Chryso Southern Africa, a program was established where tailings samples were tested at a laboratory to determine a mix design for the testing phase. Results from these tests were promising and Table 1 shows the mix designs proposed for further testing. 
Table 1 Different mix designs used for laboratory testing (Barker, 2006)

\begin{tabular}{lccccccc}
\hline \multirow{2}{*}{ DESCRIPTION } & SG & \multicolumn{2}{c}{ MIX A } & \multicolumn{2}{c}{ MIX B } & \multicolumn{2}{c}{ MIX C } \\
\cline { 3 - 8 } & & $\begin{array}{c}\text { Volume } \\
\text { (l) }\end{array}$ & $\begin{array}{c}\text { Mass } \\
\text { (kg) }\end{array}$ & $\begin{array}{c}\text { Volume } \\
\text { (l) }\end{array}$ & $\begin{array}{c}\text { Mass } \\
\text { (kg) }\end{array}$ & $\begin{array}{c}\text { Volume } \\
\text { (l) }\end{array}$ & $\begin{array}{c}\text { Mass } \\
\text { (kg) }\end{array}$ \\
\hline Cem 1 42.5 Powercrete & 3.14 & 159 & 500 & 159 & 500 & 64 & 200 \\
Pozzfill & 2.2 & 136 & 300 & 136 & 300 & 45 & 100 \\
CSF & 2.2 & 14 & 30 & 0 & & 0 & \\
Superpozz & 2.2 & 0 & & 14 & 30 & 18 & 40 \\
Tailings & 2.7 & 289 & 780 & 289 & 780 & 0 & \\
Wet Tailings & 1.7 & & 0 & & & 9 & 14.6 \\
Water & 1 & 415 & 415 & 380 & 380 & 40 & 40 \\
CHRYSO OPTIMA 206 & 1 & 5 & 5 & 8 & 8 & 8 & 8 \\
CHRYSOTARD CE & 1 & 5 & 5 & 5 & 5 & 6 & 6.4 \\
Total & & 1023 & 2035 & 991 & 2003 & 190 & 409 \\
SG Actual & & & 1.94 & & 1.88 & & 2.1 \\
\hline Strength Tests & & SG & $\begin{array}{c}\text { UCS } \\
\text { (MPa) }\end{array}$ & SG & $\begin{array}{c}\text { UCS } \\
\text { (MPa) }\end{array}$ & SG & $\begin{array}{c}\text { UCS } \\
\text { (MPa) }\end{array}$ \\
\hline 7 Day & & 1.99 & 21.6 & 2.09 & 26.1 & 1.96 & 18.7 \\
& Sample 1 & 1.99 & 21.9 & 2.08 & 27.3 & 1.98 & 16.5 \\
\hline
\end{tabular}

Surface spray tests were conducted to prove that the proposed mix design provides a practical alternative wetcrete that can be sprayed with conventional wetcrete machinery. Different types of fibre was used to determine the optimum composition that would achieve strengths and energy absorption as required by the mine's wetcrete strategy. The results energy absorption capacity tests of sprayed panels are shown in Table 2.

Table 2 Different fibre mix designs used for underground testing using mix C (Barker, 2006)

\begin{tabular}{|c|c|c|c|}
\hline Fibre type & Age when tested & Corrected En & sorption value \\
\hline \multirow{3}{*}{ Standard Oxy Fibre } & \multirow{3}{*}{28 days } & $617 \mathrm{~J}$ & \multirow{3}{*}{$790 \mathrm{~J}$ (Ave) } \\
\hline & & $919 \mathrm{~J}$ & \\
\hline & & $834 \mathrm{~J}$ & \\
\hline \multirow{2}{*}{ Chryso S/50 Fibre } & \multirow{2}{*}{28 days } & $474 \mathrm{~J}$ & \multirow{2}{*}{544 J (Ave) } \\
\hline & & $614 \mathrm{~J}$ & \\
\hline \multirow{2}{*}{ New Oxy Fibre ( Prelim ) } & \multirow{2}{*}{28 days } & $896 \mathrm{~J}$ & \multirow{2}{*}{774 J (Ave) } \\
\hline & & $652 \mathrm{~J}$ & \\
\hline Metalloy test fibre & 28 days & $373 \mathrm{~J}$ & $373 \mathrm{~J}$ \\
\hline Bonbex + Target Fibre & 28 days & $534 \mathrm{~J}$ & $534 \mathrm{~J}$ \\
\hline
\end{tabular}




\subsection{Underground testing}

Based on results of the above laboratory tests, a decision was made to test and prove the mix design underground using the mine's own wetcrete machinery and batching plant. Using mix design $C$ with the standard Oxy fibre as shown in Table 2 actual underground tests were done. Underground tests proved to be successful and results are shown in Table 3.

Table 3 Underground test results for mix C with standard Oxy fibres

\begin{tabular}{ccc}
\hline Site ID & Age when tested (Days) & UCS (MPa) \\
\hline 1 & $54+$ & 39 \\
2 & 28 & 34.3 \\
3 & 28 & 27.3 \\
4 & $54+$ & 45.2 \\
5 & $54+$ & 44.5 \\
6 & $54+$ & 43.7 \\
7 & $54+$ & 40.6 \\
8 & 14 & 17.2 \\
9 & 28 & 35.9 \\
10 & $54+$ & 54.6 \\
\hline
\end{tabular}

As part of quality control and ensuring that the applied product is to design specifications of $30 \mathrm{MPa}$ on the rock walls, regular core tests and cube tests were done. It became apparent in the early stages of the project that the number of additives that were added in the laboratory testing would have to be reduced due to the logistical restriction of the shaft.

It was found that the average uniaxial compressive strength of the wetcrete on the rock walls is $38 \mathrm{MPa}$, which exceeds the design criteria and can still be reduced for further cost savings for mix design C.

\subsection{Impact on business processes}

- The new system allows better utilisation of the wetcrete workforce due to improved product availability.

- Higher availability of Monorail system for other processes critical to the production process.

- Reduction in waste of raw materials in the process of transportation and storage underground.

- Unit cost of wetcrete was significantly decreased. A $25 \%$ saving in the direct cost of wetcrete is realised. Considering the total cost of the wetcrete operation, including factors such as logistics and workforce utilisation, the monthly saving is as much as $60 \%$.

- Reduced environmental impact, as more tailings material is pumped back underground instead of to storage facilities on surface. Less reliance on natural resources such as river sand.

\section{Material specifications}

Using the Q System to evaluate the rock mass on Target mine the shotcrete requirements for tunnel widths 4 $\mathrm{m}$ and $6 \mathrm{~m}$ wide could be determined. The Q System classification is based on three important aspects:

- $\quad$ Rock block size (RQD / Jn).

- Joint shear strength (Jr / Ja). 
- Confining stress (Jw / SRF).

Where: $R Q D$ is the rock quality designation.

$J_{n} \quad$ is the joint set number.

$J_{r} \quad$ is the joint roughness number.

$J_{a} \quad$ is the joint alteration number.

$J_{w} \quad$ is the joint water reduction factor.

$S R F \quad$ is the stress reduction factor.

$$
\begin{aligned}
Q & =\frac{\mathrm{RQD}}{\mathrm{J}_{\mathrm{n}}} \times \frac{\mathrm{J}_{\mathrm{r}}}{\mathrm{J}_{\mathrm{a}}} \times \frac{\mathrm{J}_{\mathrm{w}}}{\mathrm{SRF}} \\
& =\frac{75}{9} \times \frac{1.5}{2} \times \frac{1}{50} \\
& =0.13
\end{aligned}
$$

Figure 2 below is a modified graph for mining excavations in which the excavation stability ratio (ESR) is incorporated (Stacey, 2001). From the chart below the required thickness could be determined. It was found that for a tunnel with a $4 \mathrm{~m}$ wide span the minimum shotcrete thickness is $40 \mathrm{~mm}$ and for a $6 \mathrm{~m}$ wide tunnel span a $50 \mathrm{~mm}$ shotcrete thickness is recommended

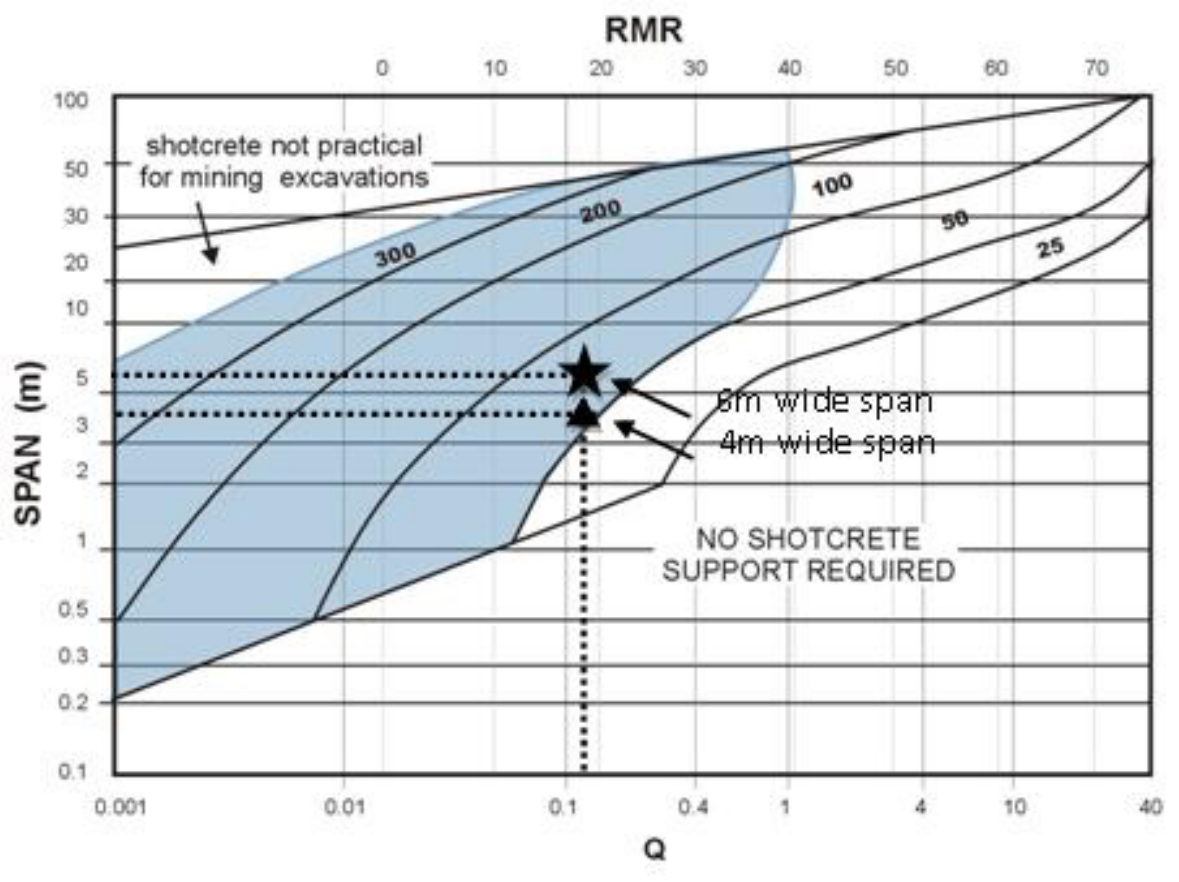

\section{Figure 2 Shotcrete support design chart (Stacey, 2001)}

The actual quantity of wetcrete that can be applied per day with the new tailings system using four Transmixers and one Spray-mac for an applied $40 \mathrm{~mm}$ thickness is $346 \mathrm{~m}^{2} / \mathrm{shift}$. For a $50 \mathrm{~mm}$ thickness $277 \mathrm{~m}^{2} /$ shift can be achieved assuming that no breakdown of equipment occurs. This equates to 25 linear metres per shift for a 5 × $4.5 \mathrm{~m}$ tunnel and 17 linear metres for a $5 \times 6 \mathrm{~m}$ tunnel.

This is significantly more than with the old wetcrete system. Due to the high quantities of wetcrete required this system can be utilised more cost effectively. 


\subsection{Aggregate}

The maximum allowable SG for the classified tailings is 1.75 at the surface Pachuca before being sent underground. If the SG is higher than this, pipe wear becomes high and the possibility of pipe blockages increases. Once underground 280 litres of tailings are required to prepare a wetcrete batch to fill a Transmixer vehicle (capacity of $0.38 \mathrm{~m}^{3}$ ).

\subsection{Strength}

For shotcrete an in-situ uniaxial compressive strength of $30 \mathrm{MPa}$ at 28 days are required.

\subsection{Thickness}

The minimum average shotcrete thickness required for a $4 \mathrm{~m}$ wide tunnel is $40 \mathrm{~mm}$ and for a $6 \mathrm{~m}$ wide tunnel is $50 \mathrm{~mm}$.

\subsection{Fibre Content}

The good performance of the Chryso Shotcrete Oxyfibres with the tailings wetcrete mix is due to the bond that it has with the cement paste. The Chryso Shotcrete Oxyfibres have been treated with a Crypsinated surface to give excellent wetting and bonding properties. The other fibres either rely on the aggregates to fibrillate the ends of the fibre for bonding or, as they are just sheet polypropylene, the cement particles have no grip or bond.

For the classified tailings wetcrete a ratio of $3 \mathrm{~kg}$ fibres per $0.38 \mathrm{~m}^{3}$ batch wetcrete is specified.

\subsection{Additives}

Additives are added at the batching plant in accordance with the ratios specified below.

The following quantities of additives are normally used:

$\begin{array}{ll}\text { Cement } & 180 \mathrm{~kg} / 0.38 \mathrm{~m}^{3} . \\ \text { Condensed Silica Fumes } & 50 \mathrm{~kg} / 0.38 \mathrm{~m}^{3} . \\ \text { Plasticiser } & 3.0 \text { litres } / 0.38 \mathrm{~m}^{3} . \\ \text { Retardant } & 3.0 \text { litres } / 0.38 \mathrm{~m}^{3} .\end{array}$

Accelerator is added at the nozzle at a rate of 1.0 litre / minute.

\section{Quality assurance}

\subsection{Aggregate}

The SG of the classified tailings are monitored and maintained at 1.75 at the surface backfill plant, through hourly sampling and testing by the batch plant operator.

\subsection{Sump tests}

Regular slump tests (using a DIN flow table) are performed as to ensure that the correct viscosity of the wetcrete is maintained. The ideal spread for slump tests is the order of $400 \mathrm{~mm}$.

All these records are kept by the batch plant operator for all test results. These test results are recorded on a control sheet, of which a copy is supplied to the Rock Engineering department on a monthly basis. This control sheet shows the date on which the test was done, the mean flow of the test specimen and the area where the wetcrete was used.

\subsection{Wetcrete cube tests}

The strength is monitored from cast cubes and is tested in the Rock Engineering Laboratory. 
For each wetcrete batch one $100 \times 100 \mathrm{~mm}$ wetcrete cube must be cast. These cube tests are done as an additional control to ensure the correct final strength is obtained.

The minimum uniaxial compressive strength for the wetcrete cubes should be $45 \mathrm{MPa}$ after 28 days as to ensure an in-situ strength of $30 \mathrm{MPa}$ on the rock walls. This relationship has been determined empirically at Target Mine using quality control data accumulated over several years.

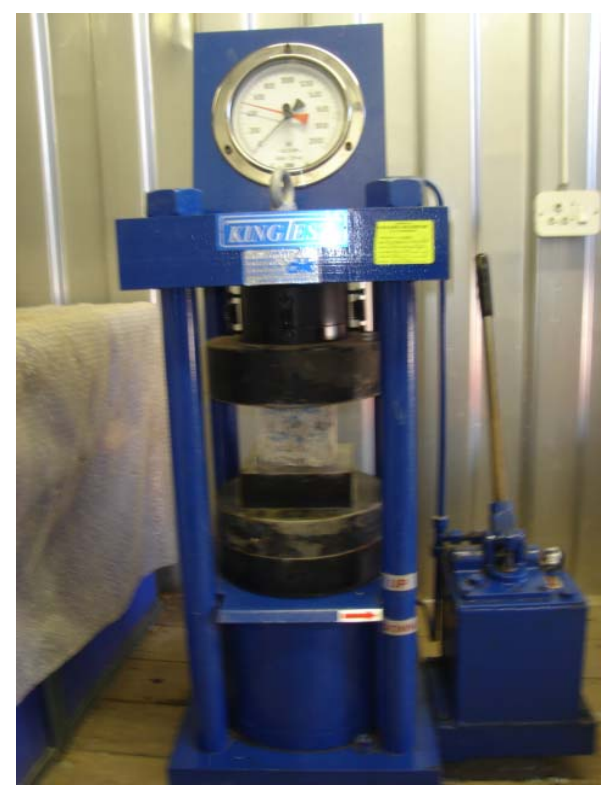

Figure 3 Cube tester

\subsection{Thickness control}

As to monitor and control the thickness of the wetcrete a thickness control punch with a protruding pin as long as the specified thickness, must be used to punch the wetcrete layer at least once every $1 \mathrm{~m}^{2}$. The wetcrete must be applied until the disk on the punch makes a $\pm 2 \mathrm{~mm}$ deep impression in the wetcrete.

\subsection{In-Situ core tests}

The strength is monitored from cast cubes and cores drilled from the wetcrete walls and tested in the Rock Engineering Laboratory. Every ten linear metres, a block of $500 \times 500 \times 100 \mathrm{~mm}$ thick is sprayed on the sidewall at grade elevation as shown in Figure 4. Two cores samples are taken from these panels and tested to confirm the Uniaxial Compressive Strength of at least $30 \mathrm{MPa}$.

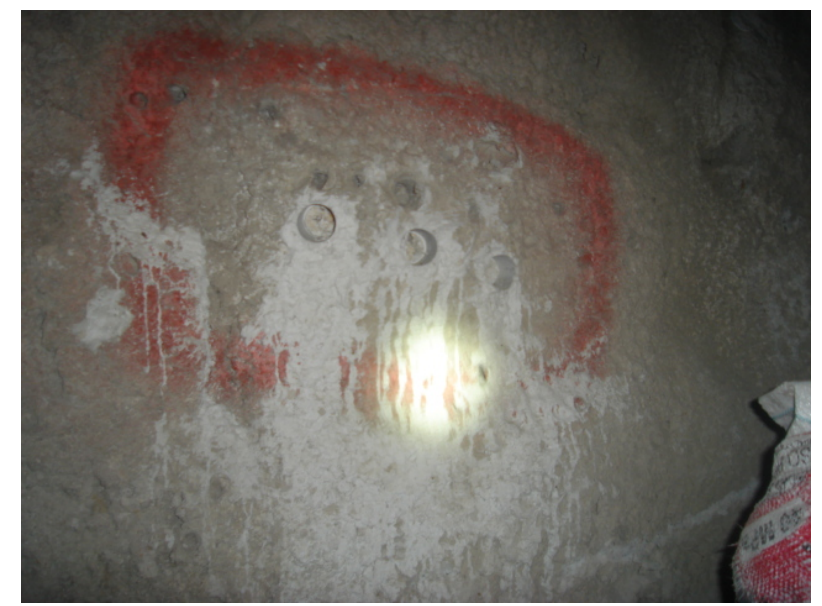

Figure 4 Photo showing the cores drilled out of the sidewall at grade elevation 


\subsection{Tensile and bond strength test}

Using a DPG100 tester from Hilti the tensile strength and bond strength to bare rock of the shotcrete is tested as shown in Figure 5.

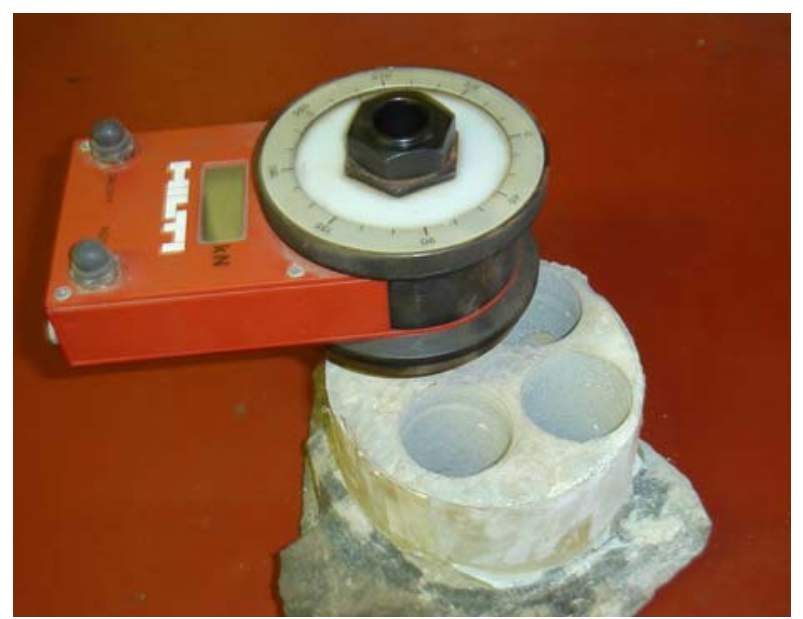

Figure 5 DPG100 tester from Hilti, testing the bond strength

\subsection{Energy absorption capacity plate test}

This is mainly done to fine tune the design of the tailings wetcrete and is not done on regular intervals. The energy absorption required is $700 \mathrm{~J}$.

\section{Future work}

This project changed the way in which wetcrete is being viewed. In future even more cost savings can be achieved if the SG of the product being pumped from surface to underground can be increased. If this can be achieved the product that is required to be applied to the rock wall, can actually be mixed on surface. Research should be done on new ways of pumping tailings wetcrete with a SG of $>2$ from surface to the underground batch plant.

\section{Conclusions}

In the modern competitive mining environment, the challenge will always be for engineers to provide creative and innovative ways of solving engineering problems. Tailings wetcrete provides an opportunity to not only solve logistical problems at Target Mine, but also to increase the amount of wetcrete sprayed per month in order to eliminate backlog and reduce the risk profile at the mine.

It was found that the average uniaxial compressive strength of the wetcrete on the rock walls is $38 \mathrm{MPa}$, which exceeds the design criteria. Thus there is still some design work to be done in reducing the strength to $30 \mathrm{MPa}$ for further cost savings.

\section{Acknowledgements}

The authors wish to thank the management of Harmony Gold, Mr B Reddy for permission to publish this article. Furthermore, the management of BLA and SRK Consulting is thanked for their encouragement in the preparation of this material.

\section{References}

Barker, M. (2006) Chryso Chemicals, personal communication, consultancy reports.

Ras, D.J. and Basson, F.R.P. (2002) Brief overview of the geotechnical aspects at Target Mine, Internal presentation.

Stacey, T.R. (2001) Best practice rock engineering, handbook for “other” mines, SRK Consultancy, pp. 12-141.

Van Vuuren, F. (2006) Electro Hydro World (grout plant specialists), personal communication. 